and direction of science vary greatly over the surface of the globe. Scientists have special knowledge of science, and in virtue of this they have the responsibility of seeing that the public is correctly informed on scientific matters which affect public affairs.

The World Federation seeks to keep in touch, and collaborate, with other international bodies concerned with science, such as the United Nations Educational, Scientific and Cultural Organisation, and the World Federation of Trade Unions. U.N.E.S.C.O. has already invited the Federation to send an observer to one of its panels, and it has invited the Federation to send an observer, subject to confirmation by the Conference itself, to the present U.N.E.S.C.O. Conference at Mexico City.

Another direction in which the World Federation has been able to contribute towards international understanding between scientists is in collaboration with other scientific bodies in the commemoration of scientific personalities and events of international significance. It joined with the Association of Scientific Workers and the Society for Visiting Scientists to organise meetings in memory of Paul Langevin, and it has joined with the Association des Travailleurs Scientifiques and the Syndicat National de l'Enseignement Supérieur et de la Recherche Scientifique in organising, under the patronage of the President of the French Republic and the Académie des Sciences, a meeting in Paris in commemoration of the tenth anniversary of the death of Lord Ruther. ford. The occasion will be an opportunity for remembering the great physicist, and reflecting on what has come of his work, and that of his colleagues in physics. A special feature of these meetings is that they have been organised primarily by the scientists of one country in celebration of the achievements of a scientist of another country, and have thus contributed towards the strengthening and understanding of mutual dependence and sympathy in science.

The president of the World Federation of Scientific Workers is Prof. F. Joliot-Curie, and its registered headquarters are in Paris. French-speaking inquirers can most readily receive further information about the Federation from the Secrétaire Général, 47 Boulevard St. Michel, Paris V, and English-speaking inquirers from the Secretary-General, 15 Half Moon Street, London, W.1.

\section{THE PAINT RESEARCH ASSOCIATION}

\section{By DR. L. A. JORDAN Director}

$\mathrm{T}$ HE co-operative industrial research association movement in Britain is an interesting develop. ment, whatever may have been said or written about it, particularly during the last few years. Those responsible for controlling the work of the associations and of holding together on a voluntary basis a heterogeneous membership with varied views as to what co-operative industrial research is about, are conscious of the limitations and have no illusions about the weaknesses of the system. They have the responsibility of watching the interests equally of all their members; no duty could be more difficult, and errors of judgment are not lightly tolerated. Displeasure, however transient, saps enthusiasm, without which nothing is achieved; on the other hand, confidence is a plant of slow growth, but it is essential and it can be won.

One must admit that the crux of the matter, or at least one aspect of it, is the interpretation placed by individuals on the word 'co-operative' and how it is related to the primary and universal human instinct of self-interest-which may come to be regarded as self-preservation. Research work is not the only human activity in which it must be recognized that there are degrees in co-operation, and that it does not do to strain even the best of good intentions. Fortunately for research association work, many industries have a wide background of technology waiting for first-class scientific investigation from which information may be gained acceptable to all, provided it is brought only to a certain stage. That stage is when each member firm according to inclination and capacity can take the material information offered and develop it within the ambit of the firm's interest.

Inevitably that stage is too far for some-or at least they think so; definitely not far enough for others, and certainly not far enough to ensure a widespread, rapid and effective absorption of research results into the technical administration of the industry. How to deal with that problem may give rise to differing opinions and to much honest doubt. The uneasiness so frequently expressed about the research association movement is justified in so far as it is prompted by concern as to whether means can be found to give a better overall performance, meaning the integration of the results of scientific work plus development plus utilization by the greater part of an industry.

In the meantime, while such problems are being resolved, directors of research associations have to operate the instrument provided and, coming down to a homely metaphor, the 'proof of the pudding' test still holds. If one is so minded, many quite logical and apparently sound reasons can be found why the research association idea should not work out in practice; but, in fact, the associations have not done too badly. As with most human enterprises, everything turns upon the degree of satisfaction accorded to the participants, not the least important, particularly in time of war, being the State. It is true to say that had the research associations not existed in 1939, Britain would have lacked a very powerful weapon; for the associations made it possible to mobilize at short notice in industry by industry most of the scientific and technical knowledge available, and they provided facilities for the immediate investigation of new problems under most favourable conditions.

In a number of cases, particularly those concerned with the traditional industries, associations were not easy to start; thus it was not until 1926, that is, ten years after the movement began with the establishment of the Department of Scientific and Industrial Research, that the Paint Research Association was formed. The term 'paint' in this context includes colour (that is, pigments), varnish, printing ink, certain aspects of linoleum-in fact, all those procedures which depend upon a related technology of incorporating a solid into a fluid medium.

It is pertinent to ask what the Association has done during its twenty-one years and what it proposes to do-two questions which can be taken together in so far as they can be dealt with adequately in this short statement. First, there has been too 
great a tendency to judge research associations by the flashing discovery that solves all problems. That sort of thing is good publicity while it lasts, but is erratic in its incidence; and industries vary in the opportunities they provide for that type of work. Even so, the impression left on the collective business mind is not likely to be as lasting as the proud inventor thinks is justified.

The real need is to make and hold satisfied customers who tell their friends, and that means good nourishing fare, regularly supplied; if some special treat can be provided occasionally, so much the better. The rhythm of the Paint Research Association has been steady rather than spectacular. Much diffused information on many subjects has been brought together and records annotated, interpreted, presented and used with satisfaction. A goodly portion of the scientific background of the industry has been filled in effectively, and thereby some relief has been given to the pains of scientific indigestion, arising from the flood of new chemical substances which find uses as bases for paint materials. The volume of investigational work incidental to the provision of substitutes (to use the current phrase), better described as the proper utilization of available materials, particularly during and since the War, has been very large indeed; and some useful items have been discovered in the process. The resources of the Association have been spent, for the most part, in carrying out scientific work in the laboratory on subjects (of which an indication will be given later) arising out of problems, both short-term and longterm, peculiar to the industry.

Many factors have operated everywhere during the last generation to affect the outlook of the paint and related industries; the British industries have been greatly altered as a result of research association activity. No claim is made about monetary savings arising out of the adoption of some specific process, because we have not operated that way; yet it must not be assumed that members of the Association have not benefited financially. Indeed, not a few manufacturers admit to new and profitable procedures having been developed by them as a result of direct advice from the staff, or by utilizing hints and recommendations in technical papers.

'Two years ago, a survey of the problems of the paint and allied industries was made which presented a conspectus of the field of interest, with a shorter list of collateral studies in related fields entitled. "Investigations at Present Envisaged", on the basis of which work is proceeding as circumstances permit. At the same time, appropriate reference was made to matters which had already occupied the attention of the research staff to such an extent as to have resulted in a technical paper or other publication on the subject. The number of such references is impressive.

It is usual to think of paint in terms of its colour, and that means the pigment which often gives the name to the paint. A solid powder in a liquid does not necessarily make paint, and it is reasonable to accept the view that much of scientific and technical interest is to be found in the conditions operating at the interface between the pigment and medium constituting a paint-such as the wotting and dispersion of pigments, properties which must be evaluated and assessed, or the manner in which the rheological properties and other characteristics of paints are influenced by pigment/medium volume relationships and by physical factors, that is, actual physical form and surface condition, the volume and packing characteristics and the state of flocculation of the pigment. These things, among others, determine the nature of the liquid paint, its behaviour on storage (settlement, skinning, etc.), its behaviour in use (brushing quality, opacity, spreading power, etc.), its film properties (gloss, colour, hardness, resistance and sensitivity to water attack, permeability, rust inhibition, etc.) and durability which in the first instance largely depends upon adhesion to the support. All this is not due alone to interfacial conditions; but they are very important.

The different methods of application of paint and varnish and the nature and preparation of the surface of the material painted (metals, plaster, various woods, and now plasties), the manner and mechanism of film formation, the physical relationships between coats in multiple-coat films and the significance of such matters as threshold film thickness, pigment particle and molecular orientation, are all important aspects of study, as is evidenced by the large number of technical papers and research memoranda issued, approximately 150 of each. A few of these papers, dealing with "Priming of Joinery Timber", "Painting of Plaster" (from the Building Research Station), "Painting of Non-ferrous Metals", "Preservation of Iron and Steel by means of Paint", have been available to the general public. Perhaps the most notable contribution of the Paint Research Association to public papers is the book entitled "Painting of Buildings", No. 5 in the Post-War Building Series (H.M. Stationery Office); also an important contribution has been made to the Building Research Station reports on the repair of damaged buildings.

In addition to the rather general observations made above about work relating to paints and paint application, there are seven other sections into which the technology of the related industries is divided for convenience in presentation; namely, oils, varnishes and resins, pigments and chemical colours, cellulose and other lacquers, testing, bitumens, blacks and pitches, and anti-corrosion.

Oil to the paint industry, of course, means the natural drying oils and mainly linseod oil, which is still, as it has long been, the backbone of the industry. At the present time there is a good deal of publicity being given to the problem of 'substitute linseed oil', which is not an easy problem on the large scale. During the War, great efforts were made to produce, by treatment and manipulation of other oils-castor oil in particular--a product simulating the properties of tung oil; circumstances have now changed and the urge to-day is to simulate the properties of linseed oil by treatment of one or other of the semi-drying oils. The indications are that selective solvents will permit the segregation at reasonable cost of soya bean oil, rubber seed oil or candlenut oil, and possibly others, into two fractions, one rather lower and the other correspondingly higher in iodine value, which is one of the criteria of a drying oil.

In the whole range of the drying oils, including, in addition to the types already mentioned, oiticica and various fish oils, everything depends upon treatment, mainly heat with or without air oxidation. At the far end of the treatment scale, linseed oil becomes linoxyn, the gel which is the primary linoleum base.

There are, of course, partial alternatives to drying oils, namely, materials of petroleum origin and also wool-grease; the contribution of the Paint Research Association in these fields is everywhere acknow. ledged. 


\section{No. 4071 November 8, $1947 \quad$ N A T U R E}

It is most necessary in an article of this kind to avoid the appearance of a catalogue, but there are still several sections of work to which no detailed reference has been made. Nevertheless, maybe sufficient has been said to indicate that the science involved in the study of paint is profound, and that the Paint Research Association is giving it attention.

\section{ADVANCES IN PREVENTIVE MEDICINE DURING THE WAR OF 1939-45*}

\section{By SIR ARTHUR MACNALTY, K.C.B.}

$\mathrm{D}$ URING war-time, the risks to health are many and varied; yet the essential health services of Great Britain were maintained during. the Second World War at a high level of efficiency.

Vital Statistics. The estimated mean population of persons of all ages in England and Wales was $41,246,000$ in 1939 and $37,785,000$ in 1944. There was an addition of half a million older persons during five years of war. The birth-rate, rising from 1941 onwards, reached 17.7 per thousand in 1944, the highest it has been since 1926, and the effective reproduction-rate came within one per cent of a full replacement standard. The death-rates have not notably increased. The maternal mortality-rate fell gradually from $3 \cdot 10$ per thousand total births in 1939 to the low figure of 1.92 in 1944. Through sulphonamide treatment there was a notable decline in deaths from puerperal fever and sepsis. The infant mortality-rate rose a little up to 1941, but thereafter declined, and in 1944 the rate dropped to the record figure of 45 per thousand. An outstanding feature was the low mortality of children from disease during the war years.

\section{Infectious Diseases}

Generally, the chief diseases which engaged attention during the War of 1914-18 were watched for and prevented by the same means in the Second World War. These means were the maintenance of the normal health services so far as possible; port sanitary control, which guarded against the intro. duction of infectious diseases from abroad; purity of the water supplies; notification of infectious diseases; hospital isolation; maintenance of adequate nutrition, etc.

Smallpox. In the six years, 1939-44, 28 cases occurred in England and Wales with three deaths, all in 1944. In Scotland there were three noteworthy outbreaks in 1942, affecting Glasgow, Edinburgh and Fifeshire. Infection of a severe type appears to have been imported from the East on a ship which arrived on May 29 at the Port of Glasgow. In all, there were 72 cases with 16 deaths. The outbreaks were speedily controlled through vaccination of patients and contacts, hospital isolation and disinfection.

Scarlet Fever. The incidence declined in the period 1939-42; it then increased to epidemic proportions in 1943, with some regression in 1944. The low fatality-rate fell still lower.

Measles and Whooping Cough. As a measure of war precaution, notification of measles and of

* Substance of a Chadwick Lecture given at the Town Hall, Cheltenham, on May 22, 1947. whooping cough became compulsory in England and Wales in 1940. Measles was severely epidemic in England and Wales in 1940 and 1941 ; a remission in 1942 was followed by a recrudescence in 1944, when the recorded prevalence was 158,479. The deaths in the epidemic years 1940 and 1941 were only 75 per cent of the average number in the quinquennium 1935-39, and the mortality-rate in the war years was unusually low. The recorded figures for whooping cough since 1940 indicate that the incidence of the disease is on the average much less than measles. The death-rates were not unduly high. Serum therapy gives inconclusive results, and vaccine prophylaxis, at present, seems of little avail.

Diphtheria. A striking success was achieved in the prevention of diphtheria, "the killing disease of childhood". Immunization has been encouraged by the Ministry of Health and progressive local authorities for the past fifteen years. In 1914 the campaign for mass immunization was intensified, the Ministry undertaking the free provision of prophylactics. It was roughly estimated that between 55 and 60 per cent of the child population of England and Wales had been immunized. There was a notable decline alike in the incidence and mortality of diphtheria during the war years. In 1940, when systematic immunization began, there were 46,281 notified cases with 2,480 deaths; in 1944 there were 29,949 cases with 934 deaths. Diphtheria is a preventible disease, and steady continuous effort is needed to raise the general percentage of immunized children to at least 75 .

Typhus Fever. From times immemorial, typhus fever has been favoured by war conditions. For this reason, the Medical Department of the Ministry of Health took special precautions against the risk of introduction of the disease into Great Britain. The Ministry also issued a memorandum on louse-borne typhus fever, and supplies of anti-typhus vaccines were provided.

During the War, medical research has greatly advanced the knowledge of typhus, its prevention and treatment. The principal method of checking an epidemic is effective delousing of the population at risk. "No lice, no typhus" remains the guiding rule. As is now well known, the new synthetic compound D.D.T. has a toxic effect on lice, mosquitoes and flies. By its use a serious typhus epidemic among the Italian population in Naples and southern Italy was speedily checked. Delousing and vaccine therapy can now speedily control an outbreak. The conquest of this dire disease is one of the outstanding triumphs of the war period.

Cerebro-Spinal Fever. That war favours epidemics of cerebro-spinal fever is due to overcrowding and lack of adequate ventilation in camps and billets, which assist droplet infection, and by movements of troops, which lead to the introduction of fresh and virulent strains of the meningococcus. From the end of 1914 until 1918, cerebro-spinal meningitis was epidemic on an unprecedented scale in Great Britain, the case mortality-rate averaging 72 per cent. In 1938 I directed attention to the maintained incidence of notifications of the disease and the increased number of Group I meningococcal infections. For these reasons I considered it probable that another period of epidemic prevalence was approaching, a forecast unhappily fulfilled. In 1940 the disease began rapidly to increase and continued to do so into 1941. The total of notifications in 1940 was 